\title{
Red complex periodontal pathogens are risk factors for liver cirrhosis
}

\author{
YUMIKO NAGAO $^{1,2}$ and TAKESHI TANIGAWA ${ }^{1}$ \\ ${ }^{1}$ Department of Public Health, Graduate School of Medicine, Juntendo University, Tokyo 113-8421; \\ ${ }^{2}$ Department of Pathology and Microbiology, Faculty of Medicine, Saga University, Saga 849-8501, Japan
}

Received June 24, 2019; Accepted September 23, 2019

DOI: $10.3892 /$ br.2019.1245

\begin{abstract}
Periodontal disease has been associated with liver disease; however, the identities of the periodontal disease-causing bacteria in patients with viral liver disease remain unknown. The aim of the present study was to determine the counts of the 3 periodontal pathogens that form the red complex in chronic periodontitis (Porphyromonas gingivalis, Tannerella forsythia and Treponema denticola) and 3 other bacteria (Aggregatibacter actinomycetemcomitans, Prevotella intermedia and Fusobacterium necrophorum) in patients with liver disease. A total of 47 patients with liver disease were divided into two groups based on the counts of the red complex bacteria: group A (high counts of red complex bacteria) and group B (low counts of red complex bacteria). The counts of the 6 types of bacteria in saliva and the prevalence of $P$. gingivalis-specific fimA genotype were determined. In addition, salivary occult blood tests and serological assays were performed. Univariate and multivariate logistic regression analyses were used to analyze the risk factors between the two groups of patients. Hepatitis $\mathrm{C}$ virus-related liver disease was the most frequent $(41 / 47 ; 87.2 \%)$ occurrence followed by liver cirrhosis (LC; $12 / 47 ; 25.5 \%)$ and oral lichen planus $(32 / 47$; $68.1 \%$ ). The significant risk factors between the two groups
\end{abstract}

Correspondence to: Professor Yumiko Nagao, Department of Public Health, Graduate School of Medicine, Juntendo University, 2-1-1 Hongo, Bunkyo-ku, Tokyo 113-8421, Japan

E-mail: y.nagao.qd@juntendo.ac.jp

Abbreviations: $\mathrm{HCV}$, hepatitis $\mathrm{C}$ virus; $\mathrm{HBV}$, hepatitis $\mathrm{B}$ virus; $\mathrm{CH}-\mathrm{C}$, chronic hepatitis $\mathrm{C}$; HCC, hepatocellular carcinoma; LC, liver cirrhosis; $\mathrm{PBC}$, primary biliary cholangitis; OLP, oral lichen planus; IFN, interferon; DM, diabetes mellitus; NAFLD, non-alcoholic fatty liver disease; NASH, non-alcoholic steatohepatitis; BMI, body mass index; RBC, red blood cell; WBC, white blood cell; Plt, platelet; $\mathrm{Hb}$, hemoglobin; FBS, fasting blood glucose; ALT, serum alanine aminotransferase; AST, aspartate aminotransferase; LDH, lactate dehydrogenase; ALP, alkaline phosphatase; PT, prothrombin time; T. Bil, total bilirubin; T. cho, total cholesterol; T. pro, total protein; Alb, albumin

Key words: hepatitis $\mathrm{C}$ virus, liver cirrhosis, periodontitis, red complex, oral lichen planus were LC, albumin (Alb) level, ratios of each bacteria and prevalence of the fimA II genotype. The 3 factors identified in the multivariate analysis to be associated with the red complex bacteria count were low Alb level $(<3.7 \mathrm{~g} / \mathrm{dl}), \mathrm{LC}$ and fimA II genotype, with adjusted odds ratios of $6.93,4.72$ and 4.08, respectively $(\mathrm{P}<0.05)$. These data indicated that patients with LC were at increased risk of presenting with the red complex bacteria leading to periodontal disease progression. Therefore, these patients may need to take additional care of their oral health compared with patients without LC, which may prove beneficial for the maintenance of their general health.

\section{Introduction}

According to the World Health Organization, in 2015 the estimated number of people infected with hepatitis $B$ virus (HBV) and the number of mortalities reported due to hepatitis B-related complications such as cirrhosis and hepatocellular carcinoma (HCC) were 257 and 88.7 million, respectively (1). In addition, it is estimated that 71 million people are persistently infected with hepatitis $\mathrm{C}$ virus (HCV), and the number of deaths due to hepatitis $\mathrm{C}$, mostly from liver cirrhosis (LC) and HCC, is 399,000 annually (2).

In Japan, the annual number of deaths from $\mathrm{HCC}$ is $\sim 30,000,80 \%$ of which are caused by HBV and HCV (3). The $\mathrm{HCV}$-infected patients in Japan are generally older compared with those in other countries, and a high percentage of them present with complications such as LC and/or HCC $(4,5)$.

However, in recent years, the incidence of HCC caused by viral hepatitis has decreased, whereas that of hepatitis virus-negative $\mathrm{HCC}$, or so-called non-B, non-C HCC, has increased $(6,7)$. In a nationwide multicenter study by Tateishi et al (7), the proportion of non-B, non-C HCC had increased from $10.0 \%$ in 1991 to $32.5 \%$ in 2010 . This has been attributed to the increase in alcohol consumption and the incidence of lifestyle-associated diseases, especially diabetes mellitus (DM) and non-alcoholic steatohepatitis (NASH). The number of patients with non-B, non-C HCC is expected to increase in the future.

Patients with HCV-associated liver diseases are known to have poor periodontal health with a higher incidence of oral lichen planus (OLP) and oral cancer compared with healthy people (8-10). Periodontitis is a pathological inflammatory disease of the gums and supporting bone tissues, which leads 
to tissue destruction and alveolar bone loss in response to bacterial dental plaque (11). In particular, the so-called 'red complex' bacteria comprising Porphyromonas gingivalis, Tannerella forsythia and Treponema denticola, is directly associated with the severity of periodontal diseases (12). $P$. gingivalis is a gram-negative oral anaerobe known to have a number of virulence factors, such as cysteine proteinases (gingipain), lipopolysaccharide, capsule, and fimbriae (13). T. forsythia, formerly Bacteroides forsythus, is thought to exacerbate periodontal disease via symbiosis with the highly pathogenic $P$. gingivalis and T. denticola.

Periodontal disease affects up to $50 \%$ of the adult population worldwide and severe periodontitis has been reported as the 6th most prevalent disease worldwide (14). Furthermore, it has been demonstrated to be associated with several systemic diseases $(15,16)$. Recently, studies indicating the frequent presence of $P$. gingivalis in patients with non-alcoholic fatty liver disease (NAFLD)/NASH have suggested a close association between periodontitis and NAFLD/NASH $(17,18)$.

We previously reported that the periodontal inflammatory response may be associated with liver fibrosis and obesity in patients with HCV and HBV with liver disease (19). However, studies examining the association between red complex and liver fibrosis are lacking. Therefore, in the present study, the proportion of patients with red complex in addition to liver disease was examined.

\section{Materials and methods}

Patients. A total of 47 patients with oral mucous membrane and liver disease who visited or were screened at the Saga University and Kurume University between January 2013 and February 2018 were included in this study. Informed consent was obtained from the patients, including all those who had been treated for liver disease by hepatologists, and each patient was examined by an oral surgeon. Patients on antiviral therapy [such as interferon (IFN), direct-acting antiviral therapy or nucleic acid analog for viral hepatitis infection] and antibiotic treatment were excluded from the study.

Examination of oral mucosal disease. Information regarding the daily frequency of tooth brushing, smoking habits and alcohol consumption were collected from the patients. Mucosal examinations were performed using a headlight (Welch Allyn, Ltd.) and biopsies were conducted on patients with OLP, leukoplakia and oral cancer.

Screening by salivary occult blood test. An occult blood test involves the assessment of the presence of blood, derived primarily from gingival tissues and released into the saliva. The presence of periodontal disease was considered as an indicator of periodontitis and ascertained using the Salivaster ${ }^{\circledR}$ reagent-based test (Showa Yakuhin Kako Co., Ltd.) (20). The Salivaster ${ }^{\circledR}$ is a colorimetric test based on a catalytic reaction of hemoglobin in saliva, which induces the formation of different colors ranging from yellow to dark blue. The occult blood reaction is classified as follows: Double-positive (++); positive (+) and negative (-). This method was demonstrated to have a sensitivity of $75.9 \%$ and a specificity of $90.5 \%$ for the detection of gingival inflammation (21).
Saliva sample collection. Whole saliva $(1 \mathrm{ml})$ was collected from the patients following chewing a non-flavored gum for 5 min. All samples were immediately sent to the Health Examination Laboratory (BML, Inc.) for bacterial testing (22).

Identification of periodontitis bacteria and detection of $P$. gingivalis fimA genotypes. The total number of bacteria in saliva and the counts of 6 types of periodontal pathogens (Aggregatibacter actinomycetemcomitans; Prevotella intermedia; P. gingivalis; T. forsythensis; T. denticol; Fusobacterium necrophorum) were quantified using the modified polymerase chain reaction (PCR)-Invader assay as previously described (23). Based on the ratio of each periodontal pathogen to the total bacterial count, the following criteria were used to assess the risk: i) A. actinomycetemcomitans; no risk $(<0.005 \%)$, moderate risk (0.006-0.009\%) and high risk (>0.01\%); ii) P. intermedia; no risk $(<0.09 \%)$, moderate risk $(0.1-0.49 \%)$ and high risk $(>0.5 \%)$; iii) $P$. gingivalis; no risk $(<0.09 \%)$, moderate risk $(0.1-0.49 \%)$ and high risk ( $>0.5 \%)$; iv) $T$. forsythensis; no risk $(<0.09 \%)$, moderate risk $(0.1-0.49 \%)$ and high risk $(>0.5 \%)$; v) T. denticol; no risk $(<0.09 \%)$, moderate risk $(0.1-0.49 \%)$ and high risk $(>0.5 \%)$; and vi) F. necrophorum; no risk $(<5 \%)$ and high risk $(>5 \%)$.

The patients were divided into two groups based on the proportion of the red complex bacteria as follows: Group A (high bacterial counts) and group B (low bacterial counts). Group A comprised of patients who presented with increased proportions of at least one of the 3 types of red complex bacteria, according to the aforementioned risk criteria, whereas those who demonstrated no risks for all 3 bacterial types were categorized into group B. P. gingivalis-specific fimA genotypes ranging from types I-V was detected in all the patients.

Measurement of obesity. Obesity was defined as a body mass index $(\mathrm{BMI}) \geq 25 \mathrm{~kg} / \mathrm{m}^{2}$.

Serological assays. All subjects were assessed for red blood cell, white blood cell (WBC), and platelet (Plt) counts, hemoglobin $(\mathrm{Hb})$, fasting blood glucose (FBS), and HbA1c levels; additionally, the following liver function tests were realized: Serum alanine aminotransferase (ALT); aspartate aminotransferase (AST); lactate dehydrogenase (LDH); alkaline phosphatase (ALP); prothrombin time (PT); total bilirubin (T. Bil); total cholesterol (T. cho); total protein (T. pro); and albumin (Alb). All the biochemical parameters were measured by standard clinical methods using venous blood samples taken the morning after $12 \mathrm{~h}$ overnight fast.

Evaluation of liver diseases. Anti-HCV was measured using a chemiluminescent enzyme immunoassay kit (Lumipulse II HCV; Fujirebio). HCV RNA in the serum was analyzed by using the standardized automated quantitative PCR (COBAS AMPLICOR HCV MONITOR v2.0 Test; COBAS ${ }^{\circledR}$ AmpliPrep/COBAS ${ }^{\circledR}$ Taq-Man ${ }^{\circledR}$ HCV Test; Roche Molecular Diagnostics) as reported previously $(24,25)$. Similarly, HCV genotype was determined by PCR as reported previously (26).

Ultrasonographic examinations were performed on all patients in order to investigate the shape of the liver and to identify the lesions in the organ. Computed tomography were performed on all patients. Liver biopsies were performed on patients without bleeding tendencies (i.e., those who did not 
Table I. Oral mucosal disease among the patient cohort in the present study $(n=47)$.

\begin{tabular}{lc}
\hline Characteristics & $\mathrm{N}$ \\
\hline Sex (male/female) & $17 / 30$ \\
Age, years & $70.2 \pm 8.8$ \\
Diagnosis of oral diseases & 30 \\
OLP & 1 \\
OLP, oral cancer (SCC) & 1 \\
OLP, post op of laryngeal cancer (SCC) & \\
Leukoplakia, post op of tongue cancer (SCC) & 2 \\
Sjögren's syndrome & 1 \\
Sjögren's syndrome, traumatic ulcer of tongue & 1 \\
Burning mouth syndrome & 1 \\
Cheilitis & 1 \\
No abnormality in screening for oral cancer & 9 \\
\hline
\end{tabular}

Data are presented as $\mathrm{n}$ or the mean $\pm \mathrm{SD}$. ${ }^{\mathrm{a}}$ History of laryngeal cancer treated operatively 8 years previously. OLP, oral lichen planus; SCC, squamous cell carcinoma; SD, standard deviation.

present with low platelet counts). Other potential predictors of the progression of LC, including serum Alb, T. Bil, PT and Plt were also used. The fibrosis-4 (FIB-4) index, a biomarker that has been demonstrated to be effective in assessing liver fibrosis and LC, was calculated using the following formula: Age (years) x AST (U/l)/[Plt $\left(10^{9} / 1\right) \times$ ALT $\left.(U / 1)^{1 / 2}\right](27)$. An FIB-4 index $\geq 2.67$ indicated the presence of liver fibrosis (28).

Evaluation of extrahepatic diseases. The diagnosis of type II DM was based on the criteria adopted by the American Diabetes Association in 2011 (29). Hypertension was defined as a systolic blood pressure of $\geq 140 \mathrm{mmHg}$ or diastolic blood pressure of $\geq 90 \mathrm{mmHg}$.

Statistical analysis. All data are expressed as n or mean \pm standard deviation. Differences between the two groups were analyzed using the Mann-Whitney U, Wilcoxon's and Fisher's exact tests, as appropriate. Adjusted odds ratios were calculated using logistic regression analysis. All statistical analyses were conducted using JMP v.13 (SAS Institute, Inc.). $\mathrm{P}<0.05$ was considered to indicate a statistically significant difference.

\section{Results}

Characteristic of the patients. Patient characteristics are summarized in Tables I and II. The 47 patients (17 males and 30 females) ranged in age from 49-89 years, with an average age of $70.2 \pm 8.8$ years. The most common oral mucosal disease was OLP (32/47; 68.1\%), while the other oral diseases observed were head and neck squamous cell carcinoma (4/47; 8.5\%) and Sjögren's syndrome $(2 / 47 ; 4.3 \%)$.

The rates of anti-HCV antibody and $\mathrm{HBsAg}$ positivity were $87.2 \%$ (41/47) and 2.1\% (1/47), respectively. The most common liver disease observed was chronic hepatitis $\mathrm{C}(\mathrm{CH}-\mathrm{C}$; 16/47; $34.0 \%$; Table II). In addition, 12 patients [LC and post-HCC $(\mathrm{n}=8)$; LC (n=3); and primary biliary cholangitis (PBC) $(n=1)]$ were diagnosed with cirrhosis. Biopsies were not obtained from 3 out of 12 patients with LC, due to low platelet counts.

Univariate analysis of factors associated with the two red complex groups (high vs. low). A total of 15 patients in group A exhibited high numbers of red complex bacteria, while 32 patients in group B had low numbers of the bacteria. Univariate analyses demonstrated significant associations between groups A and B (Table II). The significant factors associated with red complex bacteria count were the presence of $\mathrm{LC}(\mathrm{P}=0.0229)$ and Alb levels $(\mathrm{P}=0.0399)$. No significant differences in the levels of AST, ALT, T. cho, FBS, HbAlc, WBC, Hb, Plt, AFP and FIB-4 index were observed between the two groups. Similarly, no differences in the presence of extrahepatic manifestations, such as OLP, DM, hypertension, heart disease, thyroid disease and past history of extrahepatic cancer, BMI, smoking habits, alcohol intake, daily frequency of tooth brushing, and salivary occult blood test results were identified.

Identification and characteristics of periodontitis bacteria. Table III demonstrates the total number of bacteria in the saliva, the counts of the 6 types of periodontal bacteria, the ratios of each bacteria and the prevalence of the fimA II genotype of $P$. gingivalis. The presence of the fimA genotype II was a significant factor associated with red complex bacteria count $(\mathrm{P}=0.0310)$.

Multivariate analysis of factors associated with high counts of red complex bacteria. All variables in the univariate analyses were included in the multivariate analysis (Table IV). Three factors were associated with a high number of red complex bacteria: Alb level <3.7 g/dl; presence of LC; and P. gingivalis fimA genotype II. The adjusted odds ratios for these factors were $6.93,4.72$ and 4.08, respectively, and each was statistically significant.

\section{Discussion}

Periodontal disease is closely associated with general health: The chronic inflammatory burden of periodontal infection and the host response is associated with cardiovascular disease $(30,31)$, type II DM and insulin resistance (32), gastrointestinal and colorectal cancer (33), low term birth weight in newborn babies (34), chronic obstructive pulmonary disease (35) and Alzheimer's disease (36).

Patients with viral liver disease have poorer periodontal health compared with healthy people (8). In particular, it has been demonstrated that patients with LC tend to exhibit significant amounts of clinical attachment loss (37) and poor periodontal status $(38,39)$ when compared with healthy people. The results of a systematic review by Grønkjær (40) indicated that an increased number of patients with LC exhibited poor oral health; in addition, periodontal disease was reported in $25-69 \%$ and apical periodontitis was diagnosed in $49-79 \%$ of the patients with LC (40).

Red complex bacteria, composed of $P$. gingivalis, $T$. forsythia and $T$. denticola, serve a major role in the pathogenesis of periodontal disease (12). These bacteria are found in high numbers in periodontal lesions and deep pockets in adults (41). Recently, the 
Table II. Univariate analysis of factors associated with red complex bacteria.

\begin{tabular}{|c|c|c|c|c|}
\hline Factors & Total & $\begin{array}{l}\text { High counts of red complex } \\
\text { bacteria (group A) }\end{array}$ & $\begin{array}{l}\text { Low counts of red } \\
\text { complex bacteria (group B) }\end{array}$ & P-value \\
\hline No. subjects & 47 & 15 & 32 & \\
\hline Sex (male/female) & $17 / 30$ & $6 / 9$ & $11 / 21$ & NS \\
\hline Age, years & $70.2 \pm 8.8$ & $72.9 \pm 9.7$ & $69.0 \pm 8.2$ & NS \\
\hline Smoking history (yes) & $16(34.0)$ & $6(40.0)$ & $10(31.3)$ & NS \\
\hline Alcohol intake (yes) & $19(40.4)$ & $7(46.7)$ & $12(37.5)$ & NS \\
\hline \multicolumn{5}{|l|}{ Diagnosis of liver diseases } \\
\hline $\mathrm{CH}-\mathrm{C}$ & 16 & 4 & 12 & NS \\
\hline CH-C SVR & 8 & 1 & 7 & NS \\
\hline $\mathrm{CH}-\mathrm{C}$, post $\mathrm{HCC}$ & 4 & 2 & 2 & NS \\
\hline CH-C SVR, post HCC & 1 & 0 & 1 & NS \\
\hline $\mathrm{CH}-\mathrm{C}$, fatty liver & 1 & 0 & 1 & NS \\
\hline LC, post $\mathrm{HCC}$ & 8 & 4 & 4 & NS \\
\hline $\mathrm{LC}$ & 3 & 2 & 1 & NS \\
\hline Fatty liver & 3 & 1 & 2 & NS \\
\hline $\mathrm{PBC}$ following liver transplantation & 1 & 1 & 0 & NS \\
\hline Asymptomatic HBV carrier & 1 & 0 & 1 & NS \\
\hline Polycystic liver disease & 1 & 0 & 1 & NS \\
\hline Liver cirrhosis & $12(25.5)$ & $7(46.7)$ & $5(15.6)$ & 0.0229 \\
\hline OLP & $32(68.1)$ & $10(66.7)$ & $22(68.8)$ & NS \\
\hline Diabetes mellitus & $13(27.7)$ & $6(40.0)$ & 7 (21.9) & NS \\
\hline Hypertension & $19(40.4)$ & $6(40.0)$ & $13(40.6)$ & NS \\
\hline Heart disease & $5(10.6)$ & $1(6.7)$ & $4(12.5)$ & NS \\
\hline Thyroid disease & $6(12.8)$ & $1(6.7)$ & $5(15.6)$ & NS \\
\hline Past history of extrahepatic cancer (\%) & $11(23.4)$ & $4(26.7)$ & $7(21.9)$ & NS \\
\hline BMI, kg/m² & $23.2 \pm 3.2$ & $24.0 \pm 3.1$ & $22.8 \pm 3.2$ & NS \\
\hline Obesity (BMI $\geq 25$ ) & $14(29.8)$ & $5(33.3)$ & $9(28.1)$ & NS \\
\hline $\mathrm{AST}, \mathrm{U} / \mathrm{l}$ & $39.7 \pm 23.1$ & $49.0 \pm 27.9$ & $35.3 \pm 19.6$ & NS \\
\hline ALT, U/1 & $35.6 \pm 27.9$ & $45.3 \pm 36.6$ & $31.1 \pm 22.1$ & NS \\
\hline $\mathrm{LDH}, \mathrm{U} / \mathrm{l}$ & $205.6 \pm 51.1$ & $221.1 \pm 57.4$ & $198.6 \pm 47.3$ & NS \\
\hline ALP, U/1 & $306.1 \pm 193.9$ & $330.3 \pm 149.3$ & $294.4 \pm 213.4$ & NS \\
\hline T.pro, g/dl & $7.28 \pm 0.51$ & $7.31 \pm 0.65$ & $7.26 \pm 0.45$ & NS \\
\hline Alb, g/dl & $3.95 \pm 0.48$ & $3.74 \pm 0.46$ & $4.05 \pm 0.46$ & 0.0399 \\
\hline T. Bil, mg/dl & $0.82 \pm 0.31$ & $0.89 \pm 0.35$ & $0.79 \pm 0.28$ & NS \\
\hline Fasting glucose, $\mathrm{mg} / \mathrm{dl}$ & $114.4 \pm 47.2$ & $110.4 \pm 31.1$ & $116.5 \pm 53.9$ & NS \\
\hline $\mathrm{HbA} 1 \mathrm{c}, \%$ & $5.9 \pm 1.0$ & $5.9 \pm 1.0$ & $6.0 \pm 1.0$ & NS \\
\hline T. cho, mg/dl & $168.6 \pm 33.4$ & $178.5 \pm 37.6$ & $163.6 \pm 30.6$ & NS \\
\hline $\mathrm{RBC}, 10^{4} / \mu 1$ & $422.3 \pm 46.2$ & $424.9 \pm 37.0$ & $421.1 \pm 50.7$ & NS \\
\hline $\mathrm{Hb}, \mathrm{g} / \mathrm{dl}$ & $13.1 \pm 1.6$ & $13.5 \pm 1.3$ & $13.0 \pm 1.8$ & NS \\
\hline $\mathrm{WBC}, 10^{2} / \mu 1$ & $44.0 \pm 14.0$ & $45.3 \pm 16.0$ & $43.4 \pm 13.2$ & NS \\
\hline Plt, $10^{4} / \mu 1$ & $13.9 \pm 5.6$ & $12.6 \pm 5.2$ & $14.5 \pm 5.8$ & NS \\
\hline AFP, ng/ml & $23.9 \pm 68.9$ & $28.2 \pm 66.7$ & $22.0 \pm 71.0$ & NS \\
\hline FIB-4 index & $4.397 \pm 3.03$ & $5.23 \pm 2.89$ & $4.00 \pm 3.07$ & NS \\
\hline $\begin{array}{l}\text { Daily frequency of tooth brushing } \\
(\leq 1 \text { per day) }\end{array}$ & $7(14.9)$ & $2(13.3)$ & $5(15.6)$ & NS \\
\hline Positive salivary occult blood test & $38(80.9)$ & $13(86.7)$ & $25(78.1)$ & NS \\
\hline
\end{tabular}

Data are presented as $\mathrm{n}(\%)$ or the mean $\pm \mathrm{SD}$. CH-C, chronic hepatitis C; SVR, sustained virological response; LC, liver cirrhosis; HCC, hepatocellular carcinoma; HBV, hepatitis B virus; PBC, Primary biliary cholangitis; OLP, oral lichen planus; BMI, body mass index; AST, aspartate aminotransferase; ALT, serum alanine aminotransferase; LDH, lactate dehydrogenase; ALP, alkaline phosphatase; T. pro, total protein; Alb, albumin; T. Bil, total bilirubin; T. cho, total cholesterol; RBC, red blood cell; Hb, hemoglobin; WBC, white blood cell; Plt, platelet; AFP, alpha-fetoprotein; NS, not significant; SD, standard deviation. 


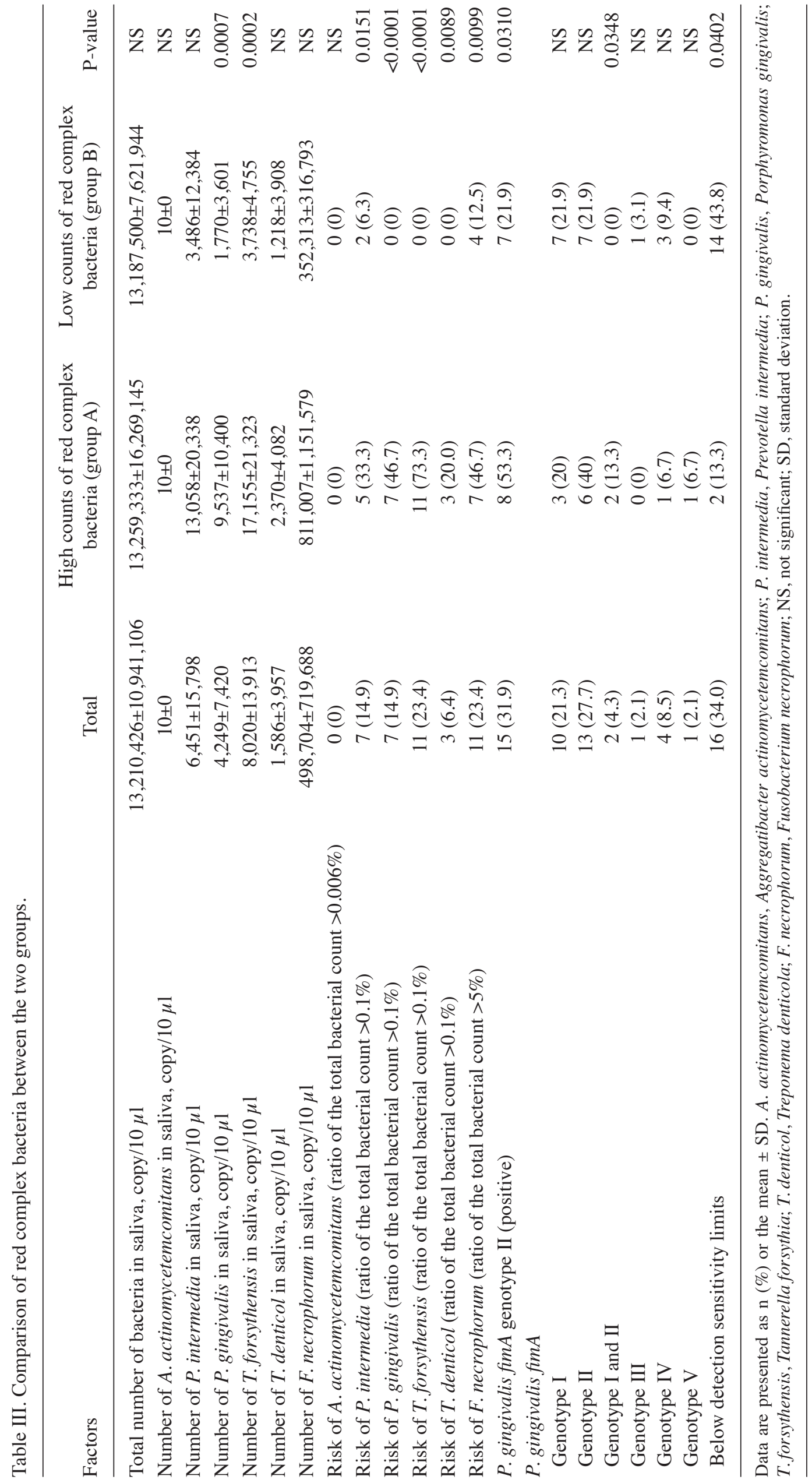


Table IV. Multivariate analysis of factors associated with high counts of red complex bacteria.

\begin{tabular}{lccc}
\hline Factor & $\begin{array}{c}\text { Odds } \\
\text { ratio }\end{array}$ & $\begin{array}{c}95 \% \text { confidence } \\
\text { interval }\end{array}$ & P-value \\
\hline Albumin $<3.7 \mathrm{~g} / \mathrm{dl}$ & 6.93 & $1.74-31.30$ & 0.0059 \\
Presence of liver cirrhosis & 4.72 & $1.20-20.27$ & 0.0263 \\
Porphyromonas gingivalis & 4.08 & $1.12-15.96$ & 0.0336 \\
fimA genotype II & & & \\
\hline
\end{tabular}

association between $P$. gingivalis and digestive system cancer, including oral squamous cell carcinoma, esophageal squamous carcinoma and pancreatic cancer, has been demonstrated in several clinical and experimental studies (42-44).

A cross-sectional study analyzing the association between oral bacteria and BMI in a healthy Japanese population demonstrated that BMI and waist circumference were independently associated with the number of red complexes (45). However, in the present study, the BMI was not significantly associated with red complex counts in both univariate and multivariate analyses. This discrepancy in results may be due to differences in the backgrounds of the subjects between the two studies. The subjects in the present study comprised elderly people with liver disease (average age, 70.2 years), and the association was analyzed by dividing the number of subjects in each group by the quantity of the red complex bacteria. Conversely, Matsushita et al (45) used the multivariate analysis of covariance to calculate the effect size of BMI for the number of components of red complex (0-3) in the healthy population (average age, 52.0 years).

In another large-scale cross-sectional study involving 997 Japanese adults, the detection rates of $P$. gingivalis, T. denticola, and T. forsythia were demonstrated to be 46.3, 76.4 and $61.1 \%$, respectively (46). P. gingivalis fimA fimbriae are classified into 6 genotypes (types I-V and Ib), based on the diversity of the fimA genes encoding the fimbrial subunits (47); they promote the adhesion of the bacteria to the gingival sites and their invasion into the tissues. It has been suggested that bacterial clones with types II/IV/Ib fim $A$ are invasive, whereas those with types I/III/V fimA are non-invasive (48).

To the best of our knowledge, the detection rate of the red complex in patients with liver disease has not been evaluated so far. In the present study, the presence of LC, hypoalbuminemia and $P$. gingivalis fimA II type were associated with high detection rates of the red complex bacteria. Hypoalbuminemia is a feature of chronic and advanced LC; therefore, it is highly likely that liver fibrosis is associated with the severity of periodontal disease. No association between the number of red complexes and HCC was observed in the present study. Although the prevalence of diabetes and extrahepatic cancer was increased in group A when compared with group B, no statistically significant difference was noted. In addition, no statistically significant differences in the levels of AST, ALT, T. cho, FBS, HbAlc, WBC, Hb, Plt, AFP and FIB-4 index, BMI, smoking habits, alcohol intake, daily frequency of tooth brushing, and salivary occult blood test results were observed between the two groups.
Certain limitations of the present study include the small sample size and the fact that the presence of periodontitis was not evaluated by determining the probing depth and bleeding on probing. Additional studies using increased numbers of patients are required.

We have previously reported the association between periodontitis and the progression of liver disease in patients infected with HCV and/or HBV (19); the 5 factors associated with periodontal disease in the study were: Decreased platelet count; tooth brushing only once a day; current IFN treatment; $\geq 65$ years of age; and obesity. Furthermore, the prevalence of $P$. gingivalis fimA genotype II was increased in patients with cirrhosis (50\%) when compared with those with non-cirrhotic CH-C (21.4\%).

Patients with LC have increased risk of developing bacterial infection and sepsis leading to sepsis-induced organ failure and mortality (49). Spontaneous bacterial peritonitis (SBP) is an infection characterized by the presence of LC. SBP pathogenesis in patients with cirrhosis is considered to be the primary consequence of bacterial translocation due to decreased intestinal peristalsis, overgrowth of enterobacteria, impaired intestinal barrier, decreased bile acid and diminished IgA levels (50). Ashare et al (51) demonstrated that $94 \%$ of the cirrhotic subjects in the study population developed bacteremia following tooth brushing; whereas the control subjects were able to overcome this condition, the subjects with cirrhosis had prolonged periods of bacteremia, indicating that patients with cirrhosis may be more susceptible to sepsis.

Oral bacteria can survive in the bloodstream and may adhere to non-oral organs and tissues, including the heart valves, carotid atheromatous plaque, brain, spleen, pancreas, liver and bone $(52,53)$. There have been a series of studies suggesting an association between oral and intestinal flora $(54,55)$. In 2014, it was demonstrated that a large proportion (54\%) of bacteria derived from the oral cavity were frequently detected amongst the intestinal flora in patients with LC, and the ratio was correlated with the severity of the disease, suggesting an invasion of the gut from the mouth in LC (54).

The problems with oral hygiene that patients with viral liver disease suffer include decreased salivary flow, elicitation of periodontal disease by insulin resistance, prolonged bleeding, poor hygiene due to pain from OLP, and medical discrimination and prejudice $(9,19,56,57)$, which may hinder radical dental treatment in patients with liver disease. In Japan, the most common place where 1,705 individuals with hepatitis felt discrimination or prejudice was the dental clinic (39.3\%) followed by the hospital and other clinics (26.3\%), nursing homes $(8.7 \%)$, community $(7.5 \%)$ and beauty salons (7.3\%) (58). However, information disclosure and education about hepatitis to the dental personnel are not sufficient. It is necessary for dentists to raise awareness about oral diseases in patients with HCV/HBV infection.

In conclusion, the red complex bacteria involved in the pathogenesis of periodontal disease was associated with LC in the present study. These data indicated that maintenance of oral hygiene is important in patients with LC in order to prevent the occurrence of periodontal disease, thereby leading to improved general health.

\section{Acknowledgements}

Not applicable. 


\section{Funding}

The present study was supported in part by a Grant-in-Aid for Scientific Research (C) (grant nos. 25463274 and 17K12012) from the Ministry of Education, Culture, Sports, Science and Technology of Japan.

\section{Availability of data and materials}

All the datasets generated and analyzed in the present study are included in this published article.

\section{Authors' contributions}

YN collected data from participants, performed the statistical analysis and wrote the manuscript. TT interpreted data and added intellectual revision. Both the authors have read and approved the final version of this manuscript for publication.

\section{Ethics approval and consent to participate}

The study protocol was approved by the Ethics Committee of Kurume University (reference no. 12240) and the Ethics Committee of Saga University (reference no. 2015-02-16) in accordance with the Declaration of Helsinki. Written informed consent for participation in the study was obtained from each patient.

\section{Patient consent for publication}

Not applicable.

\section{Competing interests}

The authors declare that they have no competing interests.

\section{References}

1. WHO: Hepatitis B Fact sheet July 2018. http://www.who.int/ mediacentre/factsheets/fs204/en/.

2. WHO: Hepatitis C Fact sheet July 2018. http://www.who.int/ mediacentre/factsheets/fs164/en/.

3. Umemura T, Ichijo T, Yoshizawa K, Tanaka E and Kiyosawa K: Epidemiology of hepatocellular carcinoma in Japan. J Gastroenterol 44 (Suppl 19): 102-107, 2009.

4. Asahina Y, Tsuchiya K, Tamaki N, Hirayama I, Tanaka T, Sato M, Yasui Y, Hosokawa T, Ueda K, Kuzuya T, et al: Effect of aging on risk for hepatocellular carcinoma in chronic hepatitis $\mathrm{C}$ virus infection. Hepatology 52: 518-527, 2010.

5. Tanaka J, Koyama T, Mizui M, Uchida S, Katayama K, Matsuo J, Akita T, Nakashima A, Miyakawa Y and Yoshizawa H: Tota numbers of undiagnosed carriers of hepatitis $\mathrm{C}$ and $\mathrm{B}$ viruses in Japan estimated by age- and area-specific prevalence on the national scale. Intervirology 54: 185-195, 2011.

6. Tateishi R, Okanoue T, Fujiwara N, Okita K, Kiyosawa K, Omata M, Kumada H, Hayashi N and Koike K: Clinical characteristics, treatment, and prognosis of non- $\mathrm{B}$, non- $\mathrm{C}$ hepatocellular carcinoma: A large retrospective multicenter cohort study. J Gastroenterol 50: 350-360, 2015.

7. Tateishi R, Uchino K, Fujiwara N, Takehara T, Okanoue T, Seike M, Yoshiji H, Yatsuhashi H, Shimizu M, Torimura T, et al: A nationwide survey on non-B, non-C hepatocellular carcinoma in Japan: 2011-2015 update. J Gastroenterol 54: 367-376, 2019.

8. Al-Sharqi AJ: Periodontal status of patients with hepatitis B viruses and $\mathrm{B}$ and $\mathrm{C}$ virus (comparative study). J Pure Appl Microbiol 12: 293-300, 2018.
9. Nagao Y, Sata M, Tanikawa K, Itoh K and Kameyama T: Lichen planus and hepatitis $C$ virus in the northern Kyushu region of Japan. Eur J Clin Invest 25: 910-914, 1995.

10. Nagao Y, Sata M, Tanikawa K, Itoh K and Kameyama T: High prevalence of hepatitis $\mathrm{C}$ virus antibody and RNA in patients with oral cancer. J Oral Pathol Med 24: 354-360, 1995.

11. Williams RC: Periodontal disease. N Engl J Med 322: 373-382, 1990.

12. Socransky SS, Haffajee AD, Cugini MA, Smith C and Kent RL Jr: Microbial complexes in subgingival plaque. J Clin Periodontol 25: 134-144, 1998.

13. Lamont RJ and Jenkinson HF: Life below the gum line: Pathogenic mechanisms of Porphyromonas gingivalis. Microbiol Mol Biol Rev 62: 1244-1263, 1998.

14. Tonetti MS, Chapple IL, Jepsen S and Sanz M: Primary and secondary prevention of periodontal and peri-implant diseases: Introduction to, and objectives of the 11th European Workshop on Periodontology consensus conference. J Clin Periodontol 42 (Suppl 16): S1-S4, 2015.

15. Falcao A and Bullón P: A review of the influence of periodontal treatment in systemic diseases. Periodontol 2000 79: 117-128, 2019.

16. Bui FQ, Almeida-da-Silva CLC, Huynh B, Trinh A, Liu J, Woodward J, Asadi H and Ojcius DM: Association between periodontal pathogens and systemic disease. Biomed J 42: 27-35, 2019.

17. Yoneda M, Naka S, Nakano K, Wada K, Endo H, Mawatari H, Imajo K, Nomura R, Hokamura K, Ono M, et al: Involvement of a periodontal pathogen, Porphyromonas gingivalis on the pathogenesis of non-alcoholic fatty liver disease. BMC Gastroenterol 12: 16, 2012.

18. Alazawi W, Bernabe E, Tai D, Janicki T, Kemos P, Samsuddin S, Syn WK, Gillam D and Turner W: Periodontitis is associated with significant hepatic fibrosis in patients with non-alcoholic fatty liver disease. PLoS One 12: e0185902, 2017.

19. Nagao Y, Kawahigashi Y and Sata M: Association of periodontal diseases and liver fibrosis in patients with HCV and/or HBV infection. Hepat Mon 14: e23264, 2014.

20. Yasui T, Tanaka S, Onozawa H, Matsumoto M, Tanaka S and Nakao S: Mass screening of periodontal diseases using new test paper for detecting salivary occult bold. Nippon Shika Hyoron 587: 189-197, 1991.

21. Kaufman E and Lamster IB: Analysis of saliva for periodontal diagnosis - a review. J Clin Periodontol 27: 453-465, 2000.

22. Tada A, Takeuchi H, Shimizu H, Tadokoro K, Tanaka K, Kawamura K, Yamaguchi T, Egashira T, Nomura Y and Hanada N: Quantification of periodontopathic bacteria in saliva using the invader assay. Jpn J Infect Dis 65: 415-423, 2012.

23. Tadokoro K, Yamaguchi T, Kawamura K, Shimizu H, Egashira T, Minabe M, Yoshino T and Oguchi H: Rapid quantification of periodontitis-related bacteria using a novel modification of Invader PLUS technologies. Microbiol Res 165: 43-49, 2010.

24. Lee SC, Antony A, Lee N, Leibow J, Yang JQ, Soviero S, Gutekunst K and Rosenstraus M: Improved version 2.0 qualitative and quantitative AMPLICOR reverse transcription-PCR tests for hepatitis $\mathrm{C}$ virus RNA: Calibration to international units, enhanced genotype reactivity, and performance characteristics. J Clin Microbiol 38: 4171-4179, 2000.

25. Sizmann D, Boeck C, Boelter J, Fischer D, Miethke M, Nicolaus S, Zadak M and Babiel R: Fully automated quantification of hepatitis $\mathrm{C}$ virus (HCV) RNA in human plasma and human serum by the COBAS AmpliPrep/COBAS TaqMan system. J Clin Virol 38: 326-333, 2007.

26. Dusheiko G, Schmilovitz-Weiss H, Brown D, McOmish F, Yap PL, Sherlock S, McIntyre N and Simmonds P: Hepatitis C virus genotypes: An investigation of type-specific differences in geographic origin and disease. Hepatology 19: 13-18, 1994.

27. Vallet-Pichard A, Mallet V, Nalpas B, Verkarre V, Nalpas A, Dhalluin-Venier V, Fontaine $\mathrm{H}$ and Pol S: FIB-4: An inexpensive and accurate marker of fibrosis in HCV infection. comparison with liver biopsy and fibrotest. Hepatology 46: 32-36, 2007.

28. Shah AG, Lydecker A, Murray K, Tetri BN, Contos MJ and Sanyal AJ; Nash Clinical Research Network: Comparison of noninvasive markers of fibrosis in patients with nonalcoholic fatty liver disease. Clin Gastroenterol Hepatol 7: 1104-1112, 2009.

29. American Diabetes Association: Diagnosis and classification of diabetes mellitus. Diabetes Care 34 (Suppl 1): S62-S69, 2011.

30. Beck JD, Slade G and Offenbacher S: Oral disease, cardiovascular disease and systemic inflammation. Periodontol 2000 23: $110-120,2000$ 
31. Beukers NG, van der Heijden GJ, van Wijk AJ and Loos BG: Periodontitis is an independent risk indicator for atherosclerotic cardiovascular diseases among 60174 participants in a large dental school in the Netherlands. J Epidemiol Community Health 71: 37-42, 2017.

32. Mealey BL and Oates TW; American Academy of Periodontology: Diabetes mellitus and periodontal diseases. J Periodontol 77: 1289-1303, 2006.

33. Whitmore SE and Lamont RJ: Oral bacteria and cancer. PLoS Pathog 10: e1003933, 2014

34. Uppal A, Uppal S, Pinto A, Dutta M, Shrivatsa S, Dandolu V and Mupparapu M: The effectiveness of periodontal disease treatment during pregnancy in reducing the risk of experiencing preterm birth and low birth weight: A meta-analysis. J Am Dent Assoc 141: 1423-1434, 2010.

35. Scannapieco FA and Ho AW: Potential associations between chronic respiratory disease and periodontal disease: Analysis of National Health and Nutrition Examination Survey III. J Periodontol 72: 50-56, 2001.

36. Sparks Stein P, Steffen MJ, Smith C, Jicha G, Ebersole JL, Abner E and Dawson D III: Serum antibodies to periodontal pathogens are a risk factor for Alzheimer's disease. Alzheimers Dement 8: 196-203, 2012.

37. Novacek G, Plachetzky U, Pötzi R, Lentner S, Slavicek R, Gangl A and Ferenci P: Dental and periodontal disease in patients with cirrhosis - role of etiology of liver disease. J Hepatol 22: 576-582, 1995

38. Movin S: Relationship between periodontal disease and cirrhosis of the liver in humans. J Clin Periodontol 8: 450-458, 1981.

39. Funatsu K, Yamada M, Kawishima Y, Nishida J, Ueno M, Ebihara Y, Mizuno Y, Oda M and Tsuchiya M: Microcirculatory disturbances of oral mucosa and periodontal disease in patients with liver cirrhosis. J Gastroenterol Hepatol 4 (Suppl 1): 99-102, 1989.

40. Grønkjær LL: Periodontal disease and liver cirrhosis: A systematic review. SAGE Open Med 3: $2050312115601122,2015$.

41. Farias BC, Souza PR, Ferreira B, Melo RS, Machado FB, Gusmão ES and Cimões R: Occurrence of periodontal pathogens among patients with chronic periodontitis. Braz J Microbiol 43: 909-916, 2012

42. Katz J, Onate MD, Pauley KM, Bhattacharyya I and Cha S: Presence of Porphyromonas gingivalis in gingival squamous cell carcinoma. Int J Oral Sci 3: 209-215, 2011.

43. Ahn J, Segers S and Hayes RB: Periodontal disease, Porphyromonas gingivalis serum antibody levels and orodigestive cancer mortality. Carcinogenesis 33: 1055-1058, 2012.

44. Michaud DS, Izard J, Wilhelm-Benartzi CS, You DH, Grote VA, Tjønneland A, Dahm CC, Overvad K, Jenab M, Fedirko V, et al: Plasma antibodies to oral bacteria and risk of pancreatic cancer in a large European prospective cohort study. Gut 62: 1764-1770, 2013.

45. Matsushita K, Hamaguchi M, Hashimoto M, Yamazaki M, Yamazaki T, Asai K, Yamori M, Bessho K, Toda H, Hasegawa G, et al: The novel association between red complex of oral microbe and body mass index in healthy Japanese: A population based cross-sectional study. J Clin Biochem Nutr 57: 135-139, 2015.
46. Chigasaki O, Takeuchi Y, Aoki A, Sasaki Y, Mizutani K, Aoyama N, Ikeda Y, Gokyu M, Umeda M, Ishikawa I, et al: A cross-sectional study on the periodontal status and prevalence of red complex periodontal pathogens in a Japanese population. J Oral Sci 60: 293-303, 2018.

47. Hamada S, Fujiwara T, Morishima S, Takahashi I, Nakagawa I, Kimura S and Ogawa T: Molecular and immunological characterization of the fimbriae of Porphyromonas gingivalis. Microbiol Immunol 38: 921-930, 1994.

48. Amano A, Nakagawa I, Kataoka K, Morisaki I and Hamada S: Distribution of Porphyromonas gingivalis strains with fimA genotypes in periodontitis patients. J Clin Microbiol 37: 1426-1430, 1999.

49. Gustot T, Durand F, Lebrec D, Vincent JL and Moreau R: Severe sepsis in cirrhosis. Hepatology 50: 2022-2033, 2009.

50. Thalheimer U, Triantos CK, Samonakis DN, Patch D and Burroughs AK: Infection, coagulation, and variceal bleeding in cirrhosis. Gut 54: 556-563, 2005

51. Ashare A, Stanford C, Hancock P, Stark D, Lilli K, Birrer E, Nymon A, Doerschug KC and Hunninghake GW: Chronic liver disease impairs bacterial clearance in a human model of induced bacteremia. Clin Transl Sci 2: 199-205, 2009.

52. Van Dyke TE and van Winkelhoff AJ: Infection and inflammatory mechanisms. J Periodontol 84 (Suppl 4): S1-S7, 2013.

53. Scannapieco FA: The oral microbiome: Its role in health and in oral and systemic infections. Clin Mic News 35: 163-169, 2013.

54. Qin N, Yang F, Li A, Prifti E, Chen Y, Shao L, Guo J, Le Chatelier E, Yao J, Wu L, et al: Alterations of the human gut microbiome in liver cirrhosis. Nature 513: 59-64, 2014.

55. Nakajima M, Arimatsu K, Kato T, Matsuda Y, Minagawa T, Takahashi N, Ohno H and Yamazaki K: Oral administration of $P$. gingivalis induces cysbiosis of gut microbiota and impaired barrier function leading to dissemination of enterobacteria to the liver. PLoS One 10: e0134234, 2015.

56. Nishimura F and Murayama Y: Periodontal inflammation and insulin resistance--lessons from obesity. J Dent Res 80: 1690-1694, 2001.

57. Nagao Y, Hanada S, Shishido S, Ide T, Kumashiro R, Ueno T and Sata M: Incidence of Sjögren's syndrome in Japanese patients with hepatitis C virus infection. J Gastroenterol Hepatol 18: 258-266, 2003.

58. Tatsuoka S: Issue record of 'Research to understand the actual situation of prejudice and discrimination against hepatitis virus infected people, and to prepare guidelines for prevention of the damage' by Health, Labour and Welfare Sciences Research Grants. 2011-2013 (In Japanese).

This work is licensed under a Creative Commons Attribution-NonCommercial-NoDerivatives 4.0 International (CC BY-NC-ND 4.0) License. 